\title{
Comparison of Transcutaneous and Total Serum Bilirubin in Newborns of 34 or More Weeks of Gestation
}

\author{
Diptirekha Satapathy ${ }^{1}$, Niranjan Mohanty ${ }^{2}$ \\ ${ }^{1}$ Senior Resident, KIMS, Bhubaneswar, ${ }^{2}$ Professor, MKCG Medical College, Brahmapur.
}

\section{Abstract}

Background: Measuring the bilirubin concentration with accuracy is essential for diagnosis and proper management of neonatal hyperbilirubinemia. Serum bilirubin (TSB) is considered as the gold standard, but it takes some time.It is painful for the baby and expensive and stressful for the parents. Transcutaneous bilirubin $(\mathrm{TcB})$ can be measured without pain and is very fast. Aim of the study: To assess if $\mathrm{TcB}$ measurement can be an effective alternate screening test for diagnosing neonatal hyperbilirubinemia. Subjects and Methods: A total of 97 newborns with clinical jaundice were enrolled. Before the initiation of phototherapy, venous blood for TSB measurement was drawn. Within 30 minutes Drager's bilirubinometer JM-103 measured TcB on the infants' sternum. Simple linear regression analysis determined the relation between TcB and TSB values. The strength of the relationship and agreement between these two methods was calculated by Pearson's correlation coefficient " $\mathrm{r}$ " and Bland-Altmann plot respectively. Results: The TcB correlated well with TSB(r=0.95, 95\% confidence interval= 0.93 to 0.97 ). The mean deviation and variability ( $\pm 2 \mathrm{SD}$ ) of TcB from TSB were 0.8 and $\pm 2.5 \mathrm{mg} / \mathrm{dl}$ respectively. There was a good agreement between TcB and TSB. Conclusion: Our study showed that TcB checking can be applied as a valuable screening tool in neonates with clinically suspected jaundice.

Keywords: Hyperbilirubinemia, Neonatal, Bilirubin, Medical Laboratory Science.

Corresponding Author: Dr. Diptirekha Satapathy, Senior Resident, NICU, Department of Pediatrics, Kalinga Institute of Medical Sciences, Patia, Bhubaneswar.

Received: August 2018

Accepted: September 2018

\section{Introduction}

Neonatal hyperbilirubinemia is quite common in newborn babies and sometimes it leads to kernicterus. Early diagnosis and prompt intervention is required to prevent neurological dysfunction. Total Serum Bilirubin (TSB) estimation is the gold standard for estimating the neonatal hyperbilirubinemia. TSB estimation is invasive, painful and stressful. Transcutaneous Bilirubin (TcB) estimation is a newer noninvasive technique that was introduced in 1980 by Minolta, but was not accepted due to questionable reliability. Newer modifications of the device were produced to rectify the problems. In recent years JM-103 bilirubinometer by Drager has come out with promise of higher reliability, consistency and less variability among skin tones. The machine measures the amount of bilirubin in subcutaneous tissue by its optical system. The presence of amount of melanin and maturity of skin tends to change the actual value, but the bilirubinometer aims to account for those too.

\section{$\underline{\text { Aim }}$}

The aim of this cross sectional study was to determine whether TcB values measured by JM-103 bilirubinometer by Drager correlate with TSB levels and thereby used as a screening test in neonates born at 34 or more weeks of gestation age in Eastern Indian Population.

\section{Subjects and Methods}

This study was done from January 2015 to February 2015, in a medical college and hospital run by Government of Odisha, a state in the eastern part of India. Institutional ethical committee clearance was obtained. Newborn babies with gestational age of $>=34$ weeks and less than 15 days duration who were clinically jaundiced, but otherwise asymptomatic were enrolled for the study. After explaining the procedure to the mothers we obtained informed consent from 97 cases. Before initiation of phototherapy venous blood was obtained for TSB. The TSB measured by the diazonium method. For the entire study period we ensured that the instrumentations, the methodology and the calibrators are not changed in the government laboratory it was done.

Within 20 minutes of obtaining blood sample from the baby for TSB, the bilirubinometer was used on the sternum 


\section{Satapathy d Mahanty; Camparisan of Transcutaneous and I atal Serum Bilirulin}

[Figure 1]. The result obtained was noted. After 10 minutes another observer (one of the other authors) measured TcB with the same bilirubinometer. After 10 more minutes the earlier observer obtained $\mathrm{TcB}$ values from the sternum. The three values of $\mathrm{TcB}$ were collected and their average was derived. The corresponding TSB values were documented.

\section{Statistical Analysis}

These data were analysed in MedCalc a statistical programme specifically designed for medical professionals. A simple linear regression analysis was done to find out the relation between TcB and TSB values. Pearson's correlation coefficient ' $r$ ' and Bland-Altman plot was used to find out the strength of the relationship and the agreement between these two methods respectively.

\section{Results}

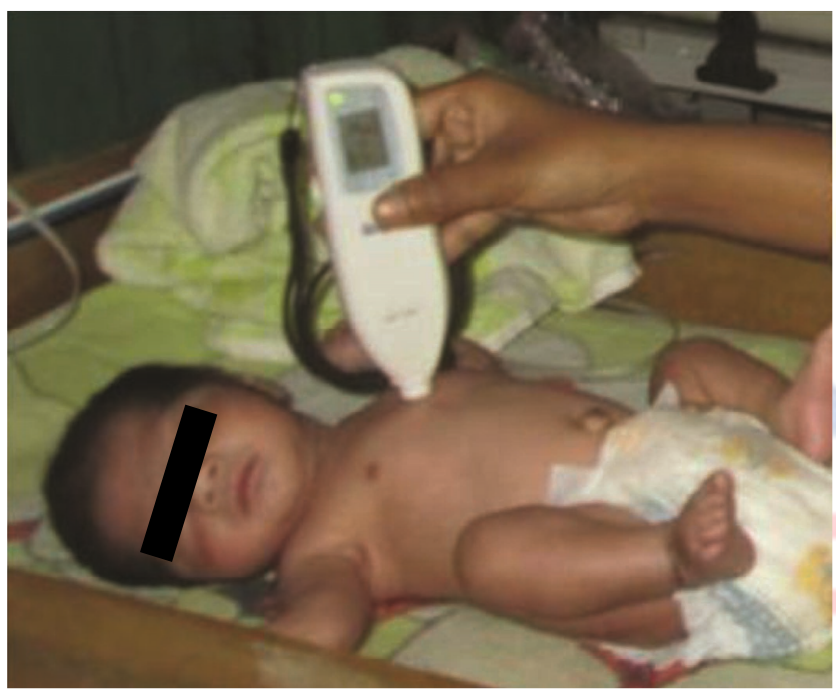

Figure 1: Technique of Transcutaneous Bilirubin measurement by JM103 bilirubinometer.

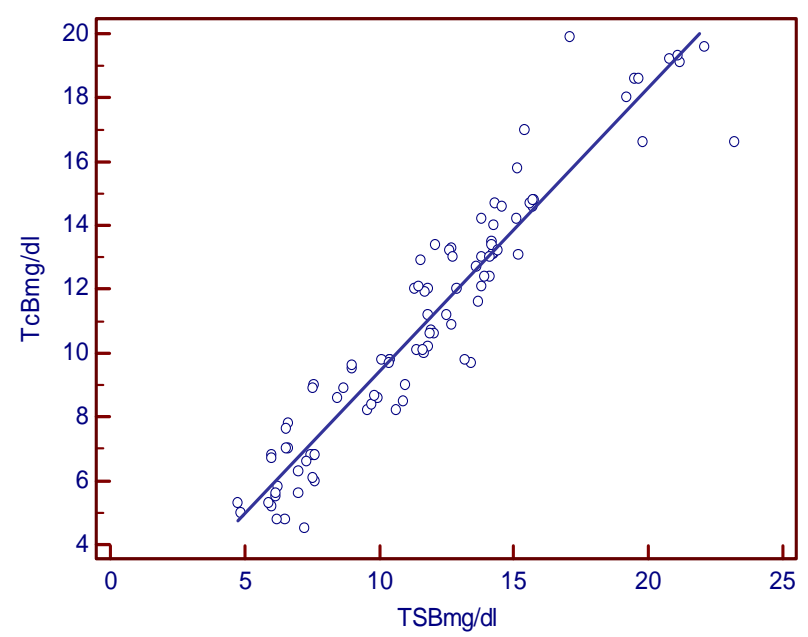

Figure 2: Scatter diagram with regression line
TSB value in the studied population ranged from 4.74 to $23.2 \mathrm{mg} / \mathrm{dl}$. The mean value was 11.75 , standard deviation was 4.25 and standard error of mean was 0.43 . The average

of $\mathrm{TcB}$ values ranged from $4.5 \mathrm{mg} / \mathrm{dl}$ to $19.9 \mathrm{mg} / \mathrm{dl}$. The mean of TcB was $10.98 \mathrm{mg} / \mathrm{dl}$, standard deviation was 3.97 and standard error of mean was 0.4 .

TcB correlated well with TSB ( $\mathrm{r}=0.95,95 \%$ confidence interval $=0.93$ to $0.97, \mathrm{p}<0.0001$ ). The mean deviation and variability (+/-2SD) of TcB from TSB were 0.8 and $+/-2.5$ $\mathrm{mg} / \mathrm{dl}$ respectively and $>95 \%$ of the data were within $+/$ 2SD of mean. [Figure 2] shows scatter diagram with regression line with $\mathrm{TSB}$ in $\mathrm{X}$-axis and $\mathrm{TcB}$ in $\mathrm{Y}$-axis. [Figure 3] shows the Bland-Altman plot and [Figure 4] shows the scatter diagram showing correlation between TSB and $\mathrm{TcB}$.

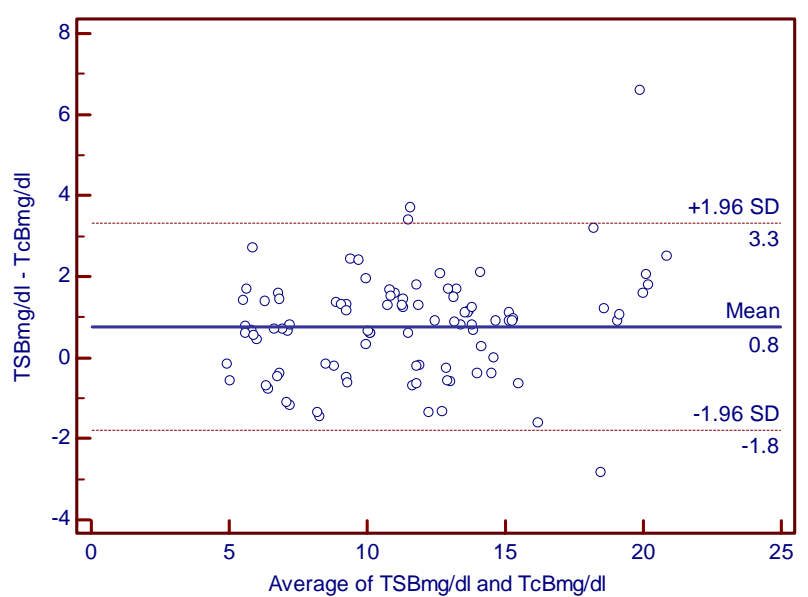

Figure 3: Bland-Altman Plot

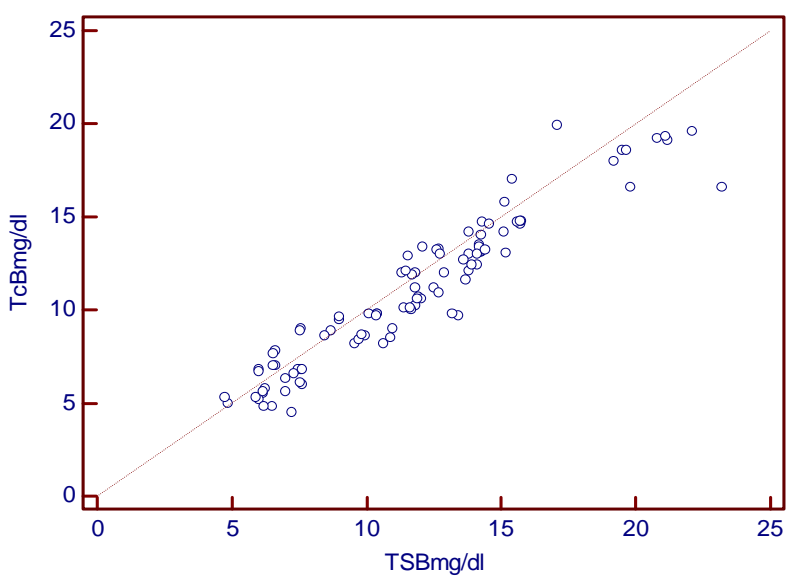

Figure 4- Correlation Scatter

\section{Discussion}

Though several studies have been done previously on this topic, there are limited studies from eastern India. This is the 


\section{Satapathy \& Mahanty; Camparisan of Transcutaneous and I atal Serum Bilirulin}

new that our study adds.

Our study was in agreement with other studies conducted in Saudi, ${ }^{[1]}$ Malawain, ${ }^{[2]}$ Iranian, ${ }^{[3]}$ Mongolian, ${ }^{[4]}$ Turkish, ${ }^{[5]}$ Chinese newborns. ${ }^{[6]}$ In a study done in United States of American, ${ }^{[7]} \mathrm{TcB}$ measurements significantly overestimated TSB levels in African American newborns. This difference was not seen in Hispanic newborns. This study also found difference in accuracy of estimating TSB in two different brands of transcutaneous bilirubinometer. However a study in Greek neonates did not find a good correlation between TcB and TSB in otherwise healthy term neonates. ${ }^{[8]}$ Though in agreement, but the correlation coefficient " $\mathrm{r}$ " between TcB and TSB measurements in our study was 0.95 which is at the higher side of previously published comparisons. Most of the earlier studies have validated TcB in relatively homogenous populations, like South Indians, ${ }^{[9]}$ Japanese, ${ }^{[4]}$ and Chinese. ${ }^{[6]}$

Our study has few limitations: 1) relatively small sample size. 2) The study was done in clinically jaundiced newborns rather than in all newborns. 3) The study was conducted before initiation of phototherapy without comparing the values after phototherapy. 4) Preterm babies born before 34 weeks of gestation were not included in this study.

More studies are required which will include newborns of all gestational ages, of different clinical conditions and will compare correlation between TcB and TSB before and after initiation of phototherapy. Future studies are also needed to create a TcB hour specific nomogram which will be much more helpful in prevention of bilirubin induced neurological damage.

\section{Conclusion}

Kernicterus is a preventable cause of neurological damage in paediatrics. So, early detection and treatment of jaundice should be the primary focus in neonatal care. The results of our study indicate that $\mathrm{TcB}$ measurements provide reasonably accurate estimates of TSB values. Hence TcB monitoring can be used as a useful screening tool for neonatal jaundice.

\section{References}

1. Alsaedi SA. Transcutaneous bilirubin measurement in healthy Saudi term newborns. Saudi Med J. 2016 Feb;37(2):142-6.

2. Rylance S, Yan J, Molyneux E. Can transcutaneous bilirubinometry safely guide phototherapy treatment of neonatal jaundice in Malawi? Paediatr Int Child Health. 2014 May 6;34(2):101-7.

3. Mansouri M, Mahmoodnejad A, Sarvestani RT, Gharibi F. A Comparison between Transcutaneous Bilirubin (TcB) and Total Serum Bilirubin (TSB) Measurements in Term Neonates. Int $\mathrm{J}$ Pediatr. 2015;3(3.1):633-41.

4. Akahira-Azuma M, Yonemoto N, Ganzorig B, Mori R, Hosokawa S, Matsushita T, et al. Validation of a transcutaneous bilirubin meter in Mongolian neonates: comparison with total serum bilirubin. BMC Pediatr. 2013;13:151.

5. Simșek FM, Narter F, Ergüven M. Comparison of transcutaneous and total serum bilirubin measurement in Turkish newborns. Turk J Pediatr. 2014:56(6):612-7.

6. Ho HT, Ng TK, Tsui KC, Lo YC. Evaluation of a new transcutaneous bilirubinometer in Chinese newborns. Arch Dis Child Fetal Neonatal Ed. 2006 Nov;91(6):F434-8.

7. Taylor JA, Burgos AE, Flaherman V, Chung EK, Simpson EA, Goyal NK, et al. Discrepancies Between Transcutaneous and Serum Bilirubin Measurements. Pediatrics. 2015 Feb 1;135(2):224-31.

8. Neocleous C, Adramerina A, Limnaios S, Symeonidis S, Spanou C, Malakozi M, et al. A comparison between transcutaneous and total serum bilirubin in healthy-term greek neonates with clinical jaundice. Prague Med Rep. 2014;115(1-2):33-42.

9. T ASA, Ganesh J, Suganya M, R NB, Sathyamoorthi B, Padmanaban S. Correlation Between Transcutaneous and Serum Bilirubin Measurements in Neonates in a Tertiary Neonatal Care Center. Int J Contemp Med Res. 2016;3(8):2340-2.

Copyright: () the author(s), publisher. Asian Journal of Clinical Pediatrics and Neonatology is an Official Publication of "Society for Health Care \& Research Development". It is an open-access article distributed under the terms of the Creative Commons Attribution NonCommercial License, which permits unrestricted non-commercial use, distribution, and reproduction in any medium, provided the original work is properly cited.

How to cite this article: Satapathy D, Mohanty N. Comparison of Transcutaneous and Total Serum Bilirubin in Newborns of 34 or More Weeks of Gestation. Asian J. Clin. Pediatr. Neonatol.2018;6(2):1-3.

DOI: dx.doi.org/10.21276/ajcpn.2018.6.2.1

Source of Support: Nil, Conflict of Interest: None declared. 